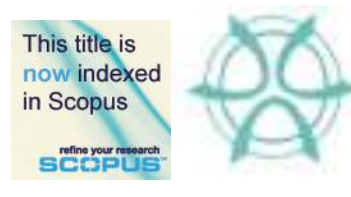

PLANNING MALAYSIA:

Journal of the Malaysian Institute of Planners

SPECIAL ISSUE IV (2016), Page 273 - 284

\title{
A DISCRETE CHOICE MODEL FOR FIRM LOCATION DECISION
}

\author{
Noordini Che' $\operatorname{Man}^{1} \&$ Harry Timmerman ${ }^{2}$ \\ ${ }^{1}$ UNIVERSITI TEKNOLOGI MALAYSIA \\ ${ }^{2}$ EINDHOVEN UNIVERSITY OF TECHNOLOGY, THE NETHERLANDS
}

\begin{abstract}
Where to locate? It is one of the most important question in locating a business in a city. In the city center, business or firms are functioning as a dominant attractor of employment and also employment locations which linked the land use and transportation system. The objective of this paper is to describe the location model of firms in Kuala Lumpur area. Two important determinants of location choice model in this study are the accessibility measures and the suitability analysis indicators. The model focuses on the statistical technique for analyzing discrete choice data by using econometric and Geographic Information System software. The findings in this paper show that agriculture, mining, electricity, gas and water, transport and finance firms' type are mostly located outside of Kuala Lumpur's Central Business District area. Meanwhile, manufacturing, construction and wholesale firms' type are located in the Central Business District area. The result of this study will highlight the use of discrete choice models in the analysis of firm location decisions which will be a foundation to facilitate town planners and decision makers to understand the firm location decisions in their region.
\end{abstract}

Keyword: Discrete Choice Modeling, Central Business District, Firm Location Decision

\section{INTRODUCTION}

Many factors influence the location of firms or businesses. Leitham et al (2000) among others identified business characteristics, the locality and the type of production. Other scholars suggested that firm location choice is based on (i) labour cost and quality; (ii) market and transportation access; (iii) interests of the pro-business community (Dipasqualea and Wheaton, 1996); (iv) economies of scale and (v) the economies of agglomeration $(\mathrm{Li}, 2007)$. Although these are not the only factors that influence the location choice, the importance of these factors varies by business sector and city.

Locating firms in the Central Business District (CBD) are important, especially in a capital city. The CBD is an area that is relatively easy to access and convenient for workers and customers/clients because of its function as a hub for all major modes of private and public transportation. The CBD area also has access to a full range of public amenities which includes services, shops, restaurants and entertainment.

For this study, the urban economy of two distinct locations was considered. The two locations are Kuala Lumpur Central Business District area and the rest of Kuala Lumpur which is its metropolitan area. The model which considers 2 locations is denoted by $\mathrm{j}=0,1$. In the study period, 1990-2007, the entry and exit of firms was examined. We 
Noordini Che'Man \& Harry Timmerman

A Discrete Choice Model for Firm Location Decision

can observe the growth and survival of a firm within the process. A firm might choose to locate in the city center where transportation cost is minimized but rents are high. Alternatively a firm also might choose to locate away from the city center where rents might be slightly lower but the transportation costs could be high. This research will give an account of discrete choice analysis of firm location decision for the Kuala Lumpur area.

\section{DISCRETE CHOICE ANALYSIS}

A discrete choice model is an econometric model in which the actors are presumed to have made a choice from a discrete set (Parson, 2004). Their decision is modelled as endogenous. Discrete Choice Analysis is used as a group of statistical techniques to model the way in which people choose between different alternatives, such as a transportation mode. The basic concept used is that each alternative has a total utility to the decisionmaker, which is the combination of the weighted utilities of all the attributes of the desired option; for example, if a university, then the quality of the university teachers, the course content, the entry requirements, distance from home, and local living costs.

It is then possible to calculate the possibility, $P$, of choosing one out of $j$ alternatives on the basis of the equation:

$P=\frac{v_{i}}{\sum v_{j}}$

where,

(Equation 1)

$i$ is the rank, by utility, of the alternative and

$v_{i}$ its utility, but the amount of data and calculation entailed is enormous.

The easiest and most widely used discrete choice model is logit because of its formula for the choice probability takes a closed form and is readily interpretable (Train, 2003). Logit model is used to model the relationship between a dependency variable $Y$ and one or more independent variables $\mathrm{X}$. The dependence variable $\mathrm{Y}$ is a discrete variable that represents a choice from a set of mutually exclusive choices. The independent variables are presumed to affect the choice and represent a priori belief about the causal or associative elements important in the choice or classification process.

This model focuses on the statistical techniques for analyzing discrete choice data using econometric software NLOGIT version 4.0 (Greene, 2008) and STATA software.

\section{Model Formulation}

\section{Random Utility model}

For the starting point for model development, consider a firm random utility derived over a single choice situation, whether to choose a location. The two outcomes are 'locate inside the CBD' and 'locate outside the CBD'. The random utility model is simply as follows: 
$\mathrm{U}($ outside $\mathrm{CBD})=\beta_{0} x_{0}+\varepsilon_{0}$

$\mathrm{U}$ (inside CBD) $=\beta_{1} x^{\prime} x_{1}+\varepsilon_{1}$

By assuming that $\varepsilon 0$ and $\varepsilon 1$ are random, the probability that the analyst will observe a location is

$$
\begin{aligned}
\operatorname{Prob}(\text { inside CBD) } & =\operatorname{Prob}(\mathrm{U}(\text { inside } \mathrm{CBD})>\mathrm{U}(\text { outside } \mathrm{CBD})) \\
& =\operatorname{Prob}\left(\beta_{1} x_{1}+\varepsilon_{1}>\beta_{0} x_{0}+\varepsilon_{0}\right) \\
& =\operatorname{Prob}\left(\varepsilon_{1}-\varepsilon_{0}<\beta_{1} x_{1}-\beta_{0} x_{0}\right) \\
& =\mathrm{F}\left(\beta_{1} x_{1}-\beta_{0} x_{0}\right)
\end{aligned}
$$

Where $\mathrm{F}(\mathrm{z})$ is the Cumulative Density Function (cdf) of the random variable $\varepsilon_{l}-\varepsilon_{0}$

\section{Binary choice model}

\section{A Case Study}

For this study, the universal choice consists of 9 types of firms. Although in the previous chapter it was 10 types of firms, because the first category represented 'undefined firms' it was dropped from this analysis. An aim of this model is to associate the firm location with its type, suitability and accessibility.

\section{Data Setup}

The data used for this analysis consist of the firm location choices of a sample of 55071 individual firms in Kuala Lumpur area not including the firm data with which haven't been classified. Table 1 shows the firm data entry between the years 1990 and 2007 in Kuala Lumpur area. 
Noordini Che'Man \& Harry Timmerman

A Discrete Choice Model for Firm Location Decision

Table 1: Firms entry by year exclude dormant firms

\begin{tabular}{cc} 
Year & Firms \\
\hline 1990 & 2401 \\
1991 & 2616 \\
1992 & 2637 \\
1993 & 3548 \\
1994 & 4099 \\
1995 & 4163 \\
1996 & 3968 \\
1997 & 3261 \\
1998 & 1696 \\
1999 & 2453 \\
2000 & 3038 \\
2001 & 2740 \\
2002 & 3095 \\
2003 & 3413 \\
2004 & 3459 \\
2005 & 3288 \\
2006 & 2947 \\
2007 & 2249 \\
\hline Total & 55071 \\
\hline Source: Company Commission Malaysia, 2009
\end{tabular}

\section{Description of the data}

For the data analysis, the data set consists total of 55071 firms, in two locations which are in the CBD and outside of the CBD. Included in the data is the information on firms type which has been categorized by 9 sectors.

\section{Original Data}

The list of the original variables in the model is as follows: 


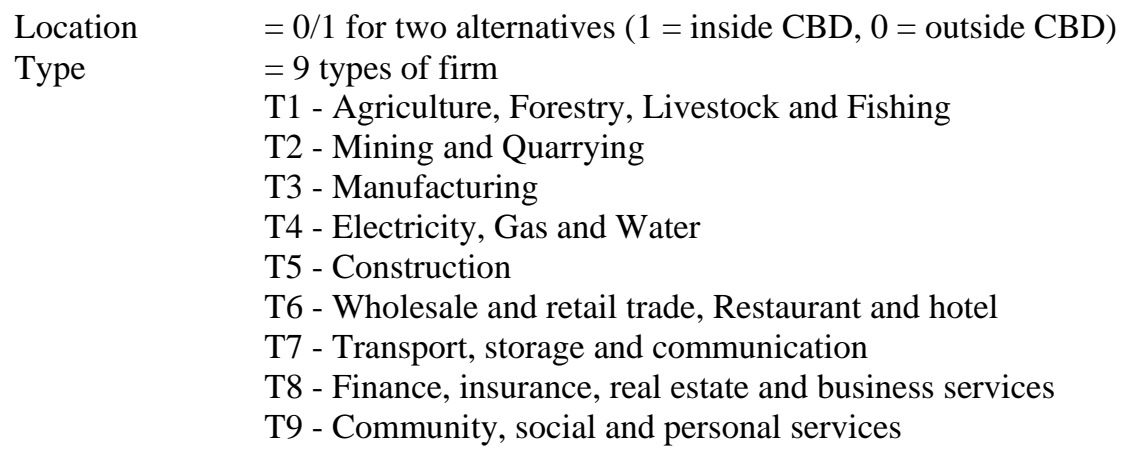

For the transformed variable, we use dummy coding and effect coding. The use of dummy coding, which is also known as an indicator variable in logistic regression, is as a variable that can take two values only, typically the values 0 or 1 to indicate the absence or presence of a characteristic. Meanwhile, effect coding provides one way of using categorical predictor variables in various kinds of estimation models, such as linear regression. Effect coding uses only ones, zeros and minus ones to convey all of the necessary information on group relationship.

For example, for every four levels of attributes, three indicator variables were constructed. The first level coded as $(1,0,0)$ which is associated with the first attribute level. The second level indicator, coded as $(0,1,0)$ which is associated with the second attribute level. The third level is coded as $(0,0,1)$ which is associated with the third attribute level. The fourth attribute level is coded $(-1,-1,-1)$ on these three indicator variables. Transformed variables for this model consist of dependent variables which are the firm location and independent variables which are the firm type, accessibility measure and suitability indicator.

\section{Transformed Data}

The transformed data categorizes as dependent variables and independent variables. The firm location variables are set as the dependent variables and the firm type, accessibility measure and suitability indicator are used as the independent variables. The details are as follows: 
Noordini Che'Man \& Harry Timmerman

A Discrete Choice Model for Firm Location Decision

\section{$\underline{\text { A - Dependent variables }}$}

\begin{tabular}{lcccc}
\hline Variable & Code & Description & Level & Dummy coding \\
Firm Location & IN & Inside CBD & 1 & 1 \\
& OUT & Outside CBD & 2 & 0 \\
\hline
\end{tabular}

$\underline{B \text { - Independent variables }}$

i)

Firm Type

\begin{tabular}{|c|c|c|c|c|c|c|c|c|c|c|c|}
\hline Variable & Code & Description & \multicolumn{4}{|c|}{ Level } & \multicolumn{5}{|c|}{ Effect coding } \\
\hline \multirow{9}{*}{$\begin{array}{l}\text { Firm } \\
\text { Type }\end{array}$} & $\mathrm{T} 1$ & $\begin{array}{l}\text { Agriculture } \\
\text { Mining \& }\end{array}$ & 1 & 1 & 0 & 0 & 0 & 0 & 0 & 0 & 0 \\
\hline & $\mathrm{T} 2$ & Quarrying & 2 & 0 & 1 & 0 & 0 & 0 & 0 & 0 & 0 \\
\hline & $\mathrm{T} 3$ & Manufacturing & 3 & 0 & 0 & 1 & 0 & 0 & 0 & 0 & 0 \\
\hline & $\mathrm{T} 4$ & $\begin{array}{l}\text { Electrical, water, } \\
\text { gas }\end{array}$ & 4 & 0 & 0 & 0 & 1 & 0 & 0 & 0 & 0 \\
\hline & T5 & Construction & 5 & 0 & 0 & 0 & 0 & 1 & 0 & 0 & 0 \\
\hline & T6 & Wholesale & 6 & 0 & 0 & 0 & 0 & 0 & 1 & 0 & 0 \\
\hline & $\mathrm{T} 7$ & $\begin{array}{l}\text { Transport \& } \\
\text { Communication }\end{array}$ & 7 & 0 & 0 & 0 & 0 & 0 & 0 & 1 & 0 \\
\hline & $\mathrm{T} 8$ & $\begin{array}{l}\text { Finance } \\
\text { Community }\end{array}$ & 8 & 0 & 0 & 0 & 0 & 0 & 0 & 0 & 1 \\
\hline & T9 & Services & 9 & -1 & -1 & -1 & -1 & -1 & -1 & -1 & -1 \\
\hline
\end{tabular}

ii) Accessibility measure

\begin{tabular}{lllcc}
\hline Accessibility measure & Code & Description & Level & Effect coding \\
\hline \multirow{2}{*}{ Highway Junction } & AH1 & High & 1 & 1 \\
& AH2 & Medium Low & 2 & -1 \\
\hline Transport Node & ANO1 & High & 1 & 1 \\
& ANO2 & Medium Low & 2 & -1 \\
\hline Road Network & SMJRD1 & High & 1 & 1 \\
& SMJRD2 & Medium Low & 2 & -1 \\
\hline \multirow{2}{*}{ Rail Network } & SRAIL1 & High & 1 & 1 \\
& SRAIL2 & Medium Low & 2 & -1 \\
\hline
\end{tabular}

iii) Suitability indicator

\begin{tabular}{cclccc}
\hline Variable & Code & Description & Level & \multicolumn{2}{c}{ Effect coding } \\
\hline River & Riv1 & Low Suitability & 1 & 1 & 0 \\
& Riv2 & Medium Suitability & 2 & 0 & 1 \\
& Riv3 & High Suitability & 3 & -1 & -1 \\
Land value & Landv1 & Low Suitability & 1 & 1 & 0 \\
& Landv2 & Medium Suitability & 2 & 0 & 1 \\
& Landv3 & High Suitability & 3 & -1 & -1 \\
Landmark & Landm1 & Low Suitability & 1 & 1 & 0
\end{tabular}




\begin{tabular}{cclccc} 
& Landm2 & Medium Suitability & 2 & 0 & 1 \\
\multirow{5}{*}{ Slope } & Landm3 & High Suitability & 3 & -1 & -1 \\
& Slope1 & Medium Suitability & 1 & 1 & \\
\multirow{3}{*}{ Amenities } & Slope2 & High Suitability & 2 & -1 & \\
& Am1 & Medium Low Suitability & 1 & 1 & \\
& Am2 & High Suitability & 2 & -1 & \\
& &
\end{tabular}

\section{RESULTS}

Maximum likelihood was used to estimate the model. The model was estimated using econometric software STATA version 10.0. The estimated parameters shown in Table 2 . As one would expect, examining the result for firms located outside of CBD verify that firm types agriculture, mining, electricity, gas and water, and transport are mostly located outside of the CBD. One surprise result is that finance firms are also mostly located outside the CBD. This result is odd and seems at variance with CBDs around the world where finance firms are invariably located in the very heart of the CBD. Is it because such firms, e.g. banks, has many branches, outlets and ATMs located near other businesses outside the $\mathrm{CBD}$ for convenience of serving their customers, with perhaps only their HQ and a few branches located within the CBD.

Meanwhile, manufacturing, construction and wholesale firms' type are located in the CBD area. This result also seems a little surprising. Manufacturing and construction firms often involve heavy bulk materials, and often require very large items for transport that are difficult to maneuver within the confines of generally narrower and more crowded road arterials in the CBD with far greater impedance factors (e.g. Not only traffic congestion and tight corners, but traffic lights and pedestrian crossings) than outside the CBD. However, in this case, this result might not surprising because the only office firm of these sectors was examined.

Table 2: Parameter estimates for firm location by type

\begin{tabular}{lc}
\hline Location & Parameter Estimates \\
Agriculture & $0.2152^{*}$ \\
Mining & $0.4033^{*}$ \\
Manufacturing & $-0.2574^{*}$ \\
Electric, Gas \& Water & $0.2361^{*}$ \\
Construction & $-0.6089^{*}$ \\
Wholesale & $-0.1126^{*}$ \\
Transportation & $0.1425^{*}$ \\
Finance & $0.2155^{*}$ \\
Community Services & $($ base type) \\
Amenities & $-1.2921^{*}$ \\
Slope & -0.0418 \\
River1 & -0.0263 \\
River2 & 0.0496 \\
Landvalue1 & 0.0198 \\
Landvalue2 & -0.0167 \\
Landmarks 1 & 0.0066 \\
Landmarks2 & -0.0116 \\
Highway & $-0.4243^{*}$ \\
Transportation Node & $-1.0963^{*}$ \\
Major Road & $-2.4304^{*}$
\end{tabular}


Noordini Che'Man \& Harry Timmerman

A Discrete Choice Model for Firm Location Decision

\begin{tabular}{lc} 
Rail Network & $-0.8493 *$ \\
\hline Goodness-of-fit statistic & -36007.60 \\
LL $(0)$ & -19086.52 \\
LL (Estimated model) & 0.470 \\
Number of parameters & \\
McFaddden's Rho-square $(\chi 2)$ &
\end{tabular}

Analyzing the influence of the accessibility indicator, most of the firms in the CBD area hold the negative coefficient which show them co-located nearby. For the stability indicator, the details were analyzed by using interaction effects.

\section{INTERACTION EFFECTS}

In order to investigate more detail on a firm's location, a firm's type and the suitability of its address inside or outside of the CBD, the interaction effect on the firm location model was performed. Interaction effects can be defined as an influence that one factor has on the other factor whereby it has a contribution of two or more variables that join together. In this interaction effect, the combination of the attributes will give an extra positive or negative effect to an alternative utility (Grigolon et.al, 2012).

In order to investigate the effects, a model containing interaction between a firm's types and location's suitability was devised. First, a model containing three-level suitability (high, medium and low) was applied. However, since it was found after running the model that the three levels were not significant, the model was simplified by merging medium and low level into only two levels (high and medium/low). Table 3 shows the result of the interaction effects.

Table 3: Result of interaction effect on firm type and the suitability

\begin{tabular}{lc}
\hline Interaction effects & Parameter Estimate \\
Interaction between predictor & \\
1. Firm type: Agriculture & \\
Agriculture and riverl & $-0.4184^{*}$ \\
Agriculture and river & $0.7541^{*}$ \\
Agriculture and raill & $0.2197^{*}$ \\
Agriculture and rail2 & $0.0755^{*}$ \\
Agriculture and node1 & $-0.2398^{*}$ \\
Agriculture and node2 & $-0.0960^{*}$ \\
Agriculture and land value1 & $-0.5997^{*}$ \\
Agriculture and land value2 & $0.3518^{*}$ \\
Agriculture and land mark1 & $0.0882^{*}$ \\
Agriculture and land mark2 & $-0.5318^{*}$ \\
Agriculture and slope & $-0.0550^{*}$ \\
Agriculture and road & $-0.3016^{*}$ \\
Agriculture and amenities & \\
2. Firm type: Mining & \\
Mining and river1 & \\
Mining and river 2 & $0.1433^{*}$ \\
Mining and raill & $-0.3153^{*}$ \\
Mining and rail2 & $0.2382^{*}$ \\
Mining and node1 & $-0.0788^{*}$ \\
\hline
\end{tabular}


Mining and node2

$0.1972 *$

Mining and land value1

$0.4770 *$

Mining and land value 2

$-0.1246 *$

Mining and land markl

$-0.0344$

Mining and land mark2

$0.4663 *$

Mining and slope

Mining and road

$-0.0836^{*}$

Mining and amenities

3. Firm type: Manufacturing

Manufacturing and river 1

Manufacturing and river 2

$-0.0003$

Manufacturing and rail1

$-0.0411$

Manufacturing and rail2

$-0.1127^{*}$

Manufacturing and node1

$0.0799 *$

0.0287

Manufacturing and node2

0.0391

Manufacturing and land value1

$-0.0331$

Manufacturing and land value 2

$0.0953^{*}$

Manufacturing and land mark1

$-0.1087 *$

Manufacturing and land mark2

$0.0759^{*}$

Manufacturing and slope

0.0045

Manufacturing and road

$-0.1570 *$

Manufacturing and amenities

$0.3628 *$

4. Firm type: Electric, Gas \& Water

Electric, Gas \& Water and riverl

$-0.4659 *$

Electric, Gas \& Water and river 2

$0.6729 *$

Electric, Gas \& Water and rail1

$0.1085^{*}$

Electric, Gas \& Water and rail2

$-0.8672^{*}$

Electric, Gas \& Water and node1

$0.4973 *$

Electric, Gas \& Water and node2

$-0.3403^{*}$

Electric, Gas \& Water and land value1

0.0273

Electric, Gas \& Water and land value 2

$-0.3197 *$

Electric, Gas \& Water and land mark1

$-0.0380$

Electric, Gas \& Water and land mark2

$0.1587 *$

Electric, Gas \& Water and slope

$1.5167 *$

Electric, Gas \& Water and road

0.4172

Electric, Gas \& Water and amenities

$-2.0837 *$

5. Firm type: Construction

Construction and river 1

$0.4630 *$

Construction and river2

$-0.4446^{*}$

Construction and raill

$-0.0729 *$

Construction and rail2

$0.2369 *$

Construction and node1

$-0.0581 *$

Construction and node 2

0.0137

Construction and land value1

$-0.0129$

Construction and land value 2

$-0.0379$

Construction and land mark1

$-0.0403$

Construction and land mark2

$-0.1467 *$

Construction and slope

$-0.8962 *$

Construction and road

0.0265

Construction and amenities

$0.4366^{*}$

6. Firm type: Wholesale 
Noordini Che'Man \& Harry Timmerman

A Discrete Choice Model for Firm Location Decision

Wholesale and river 1

$0.1517 *$

Wholesale and river2

$-0.2534 *$

Wholesale and raill

$-0.1592 *$

Wholesale and rail2

$0.1982 *$

Wholesale and node1

$-0.0222$

Wholesale and node 2

$-0.0030$

Wholesale and land value1

$-0.0447$

Wholesale and land value 2

$0.0678 *$

Wholesale and land mark1

$-0.0174$

Wholesale and land mark2

0.0146

Wholesale and slope

$-0.2304 *$

Wholesale and road

$0.0970^{*}$

Wholesale and amenities

$0.5383 *$

7. Firm type: Transportation

Transportation and river 1

Transportation and river 2

$-0.1253 *$

Transportation and rail1

0.0373

$0.0697 *$

Transportation and rail2

$-0.0118$

Transportation and node1

$-0.1926^{*}$

Transportation and node 2

$0.0867 *$

Transportation and land value1

0.0291

Transportation and land value 2

0.0153

$0.0836^{*}$

0.0329

Transportation and land mark2

$0.0622 *$

Transportation and slope

$0.0843^{*}$

Transportation and road

Transportation and amenities

8. Firm type: Finance

Finance and river 1

Finance and river 2

0.0169

Finance and raill

$-0.1409 *$

$-0.1440 *$

Finance and rail2

$0.2059^{*}$

0.0283

Finance and node1

$-0.0061$

Finance and node 2

0.0243

0.0353

Finance and land value 2

0.0230

Finance and land markI

$-0.0416$

Finance and land mark2

$-0.3507^{*}$

Finance and slope

0.0148

Finance and amenities

*Significant at 5\% level

$0.6308 *$

From the interaction effects, only the agriculture sector was identified as having a significant positive and negative effects among all suitability indicators. The significant positive effect is between agriculture and (i) river with high suitability, (ii) railways, (iii) land value high suitability and (iv) landmarks medium/low suitability. Meanwhile, the significant negative effect is with (i) river medium/low suitability, (ii) transportation node, (iii) land value medium/low suitability, (iv) landmarks high suitability, (v) slope, and (vi) major roads. 


\section{Interaction effect on firm's type and accessibility measure}

It is also interesting to examine and interpret the interaction effects on firms' type and its accessibility measure. Figure 1 shows the results. The interaction for each type of firm, illustrated different influence to the accessibility location.

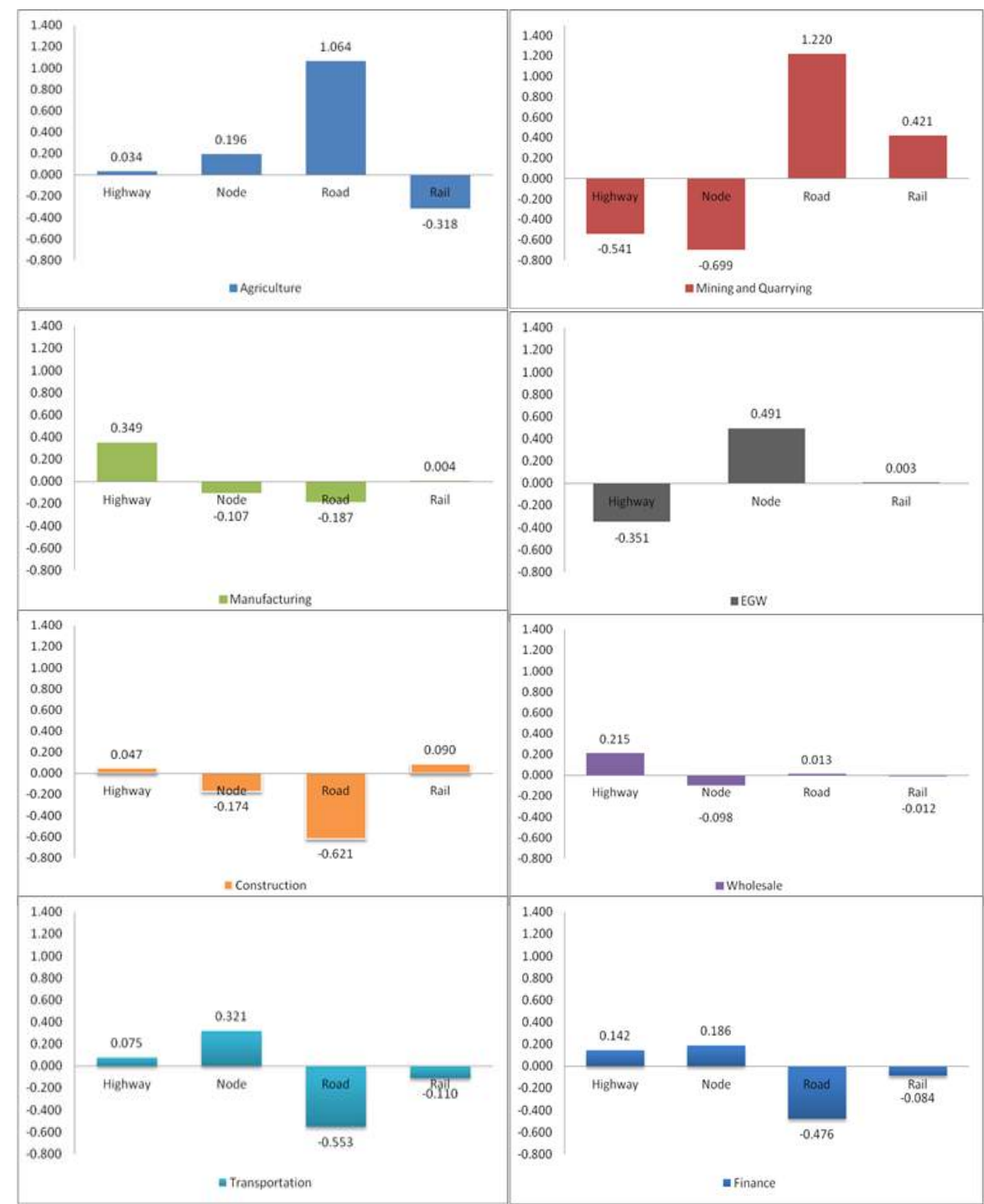

Figure 1: Result of interaction effect of firm type and accessibility measure

From Figure 1 the significant effect of each type of firm with the accessibility component is revealed. Only three sectors have positive and negative significant effects 
Noordini Che'Man \& Harry Timmerman

A Discrete Choice Model for Firm Location Decision

with the accessibility measure indicator - Mining and Quarrying, Transportation, and Finance.

\section{CONCLUSION}

The location of the firm is influenced by the accessibility and suitability indicators, especially in the CBD area. By using discrete choice modelling, the firm location in Kuala Lumpur by its sector can be identified. The results illustrated that some parameters were not significant and most probably due to the location choice of this research, limited only between areas inside and outside the CBD. Basically, the use of discrete choice models in the analysis of firm location decisions gives a foundation to facilitate town planners and decision makers to understand the firm location decisions in their region. It's hoped that the model will contribute to better knowledge and practice and helps improving the decision-making process in the future.

\section{REFERENCES}

DiPasquale, D. \& Wheaton, W.C. (1996). Urban Economics and Real Estate Markets,Prentice-Hall Incorporated: New Jersey.

Greene, W. (2008). Discrete Choice Modeling. New York, 2, 7-78.

Grigolon, A.B., Kemperman, A.D. a. M. \& Timmermans, H.J.P., (2012). Student's vacation travel: A reference dependent model of airline fares preferences. Journal of Air Transport Management, 18(1), pp.38-42.

Leitham, S., R. W. Mcquaid, and J. D. Nelson. (2000). The influence of transport on industrial location choice: A stated preference experiment. Transportation Research Part A: Policy and Practice, 34(7):515-535

Li, P. P. (2007). Towards an integrated theory of multinational evolution: the evidence of Chinese multinational enterprises as latecomers, Journal of International Management, vol. 13, pp. 296-318.

Parsons, G. (2004). Travel Cost Models. In P.Champ, K. Boyle, and T. Brown, eds. A Primer on Nonmarket Valuation. Boston: Kluwer Academic Publishers, pp. 269330.

Train, K. (2003). Discrete Choice Methods with Simulation. Cambridge University Press, Cambridge 